\title{
Stimmungsbilder von der Langen Nacht der Museen am 17. März 2012
}

Die achte Teilnahme der Württembergischen Landesbibliothek an der Langen Nacht der Museen in Stuttgart war ein voller Erfolg. Mit 2.361 Besuchern kamen fast doppelt so viele wie das Jahr zuvor. Ein besonderer Anziehungspunkt für das Stuttgarter Publikum war Eric Gauthier mit seiner Band. Der frankokanadische Tänzer und Choreograph aus dem Stuttgarter Theaterhaus begeisterte von 19 bis 1 Uhr die Besucher mit einer bunten Mischung aus Britpop und Rock. Eine Etage tiefer konnte das Stuttgarter Publikum sich in der Ausstellung über Tobias Mayer ein umfassendes Bild des Marbacher Mathematikers, Kartographen und Astronomen machen. Über 500 Gäste nahmen zudem an den weiteren Programmpunkten teil: Wie jedes Jahr fanden die Magazinführungen mit fast 300 Besuchern ein großes Interesse. Auch die neu angebotenen Führungen durch die Digitalisierungswerkstatt, bei denen auch ein Scan-Roboter vorgeführt wurde, waren allesamt ausgebucht. Schließlich lockte auch der bekannte Stuttgarter Autor Wolfgang Schorlau über 130 Krimifans zur mitternächtlichen Stunde in den Lesesaal und unterhielt sie mit einer ausgefallenen Kurzgeschichte. Für das leibliche Wohl sorgten eine Sektbar sowie eine Biertheke nebst Brezeln und griechischen Speisen.

Jörg Ennen

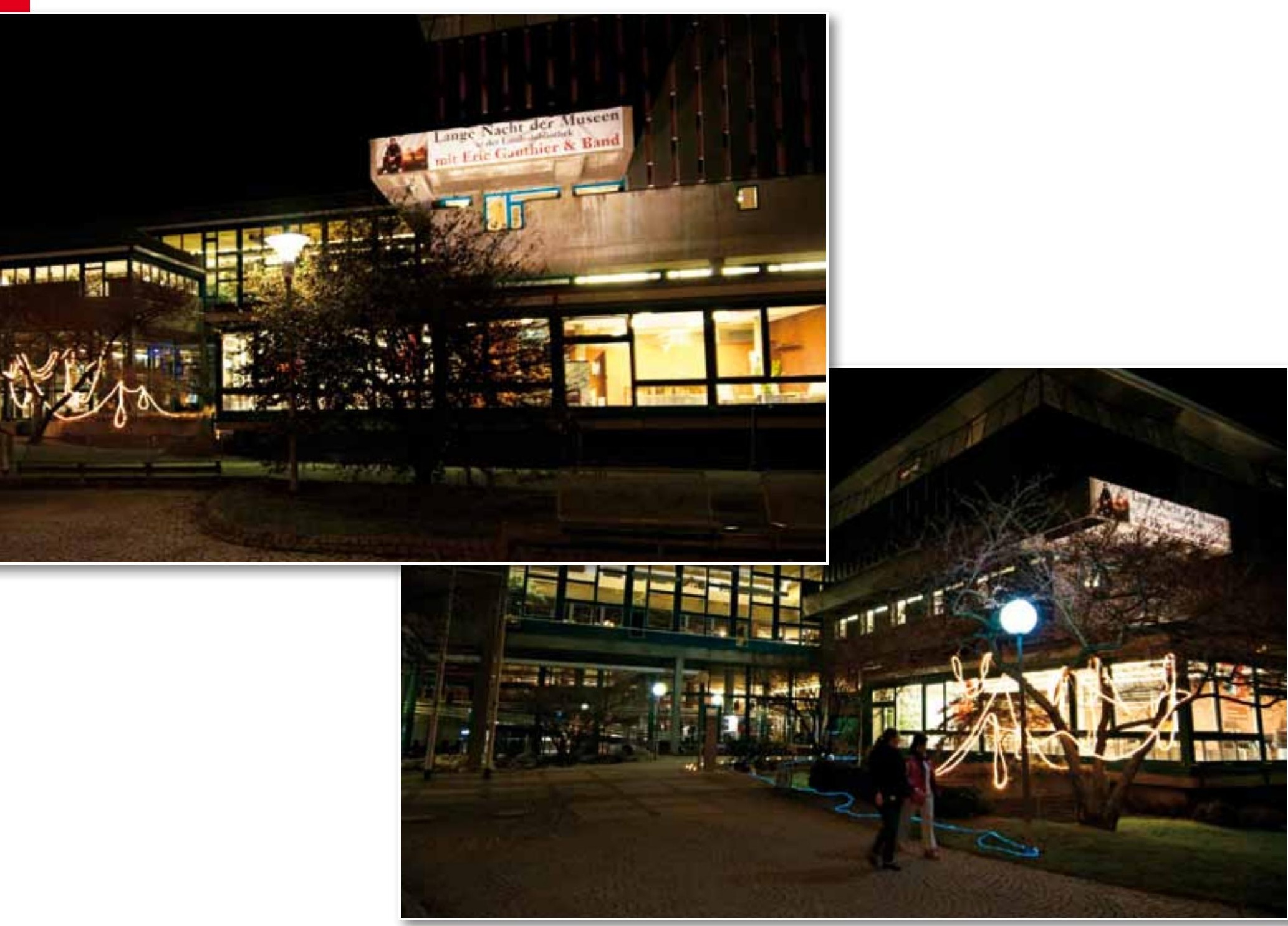




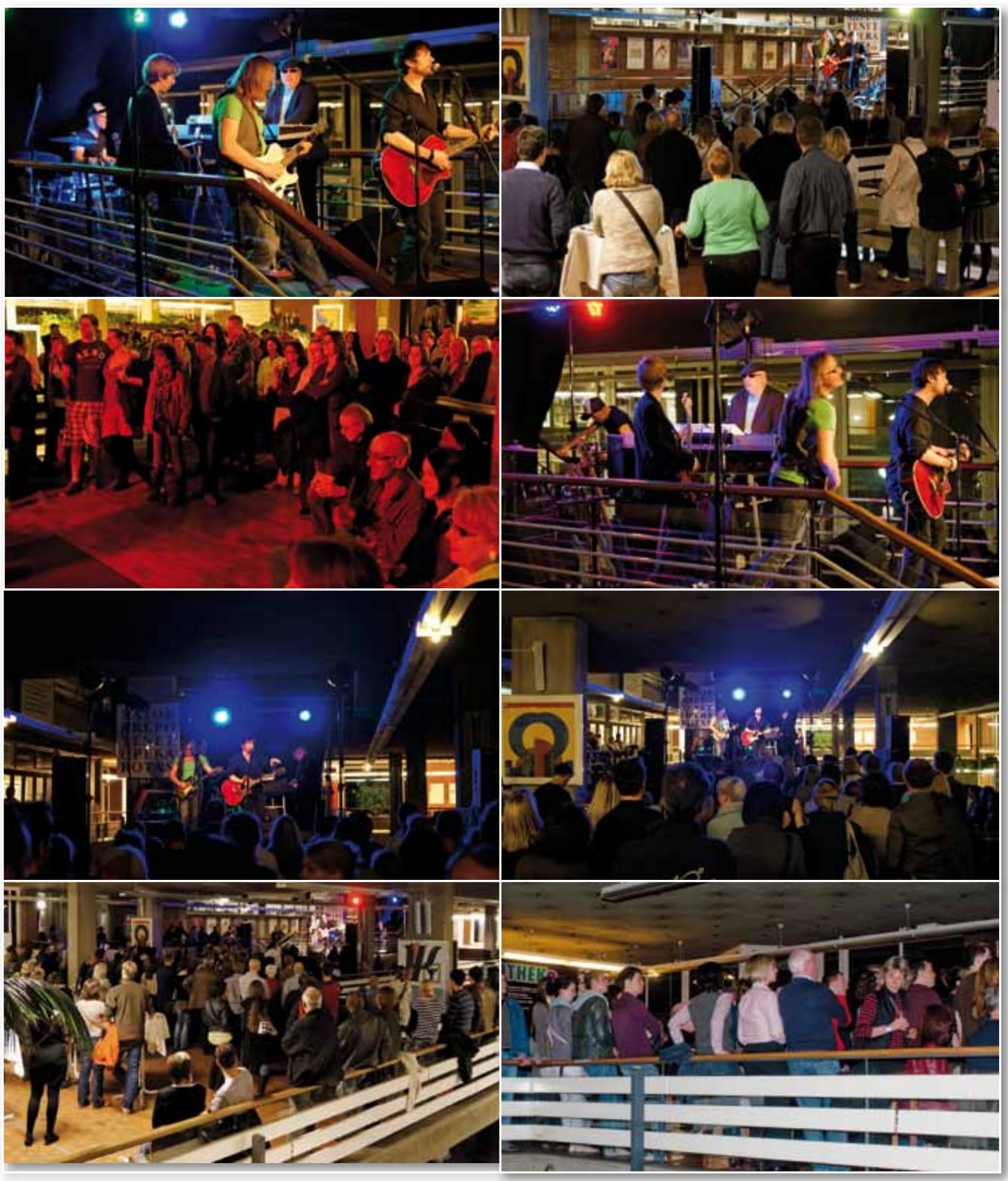

Eric Gauthier \& Band sorgten mit energiegeladenen Songs jederzeit für gute Stimmung und ein gefülltes Foyer.

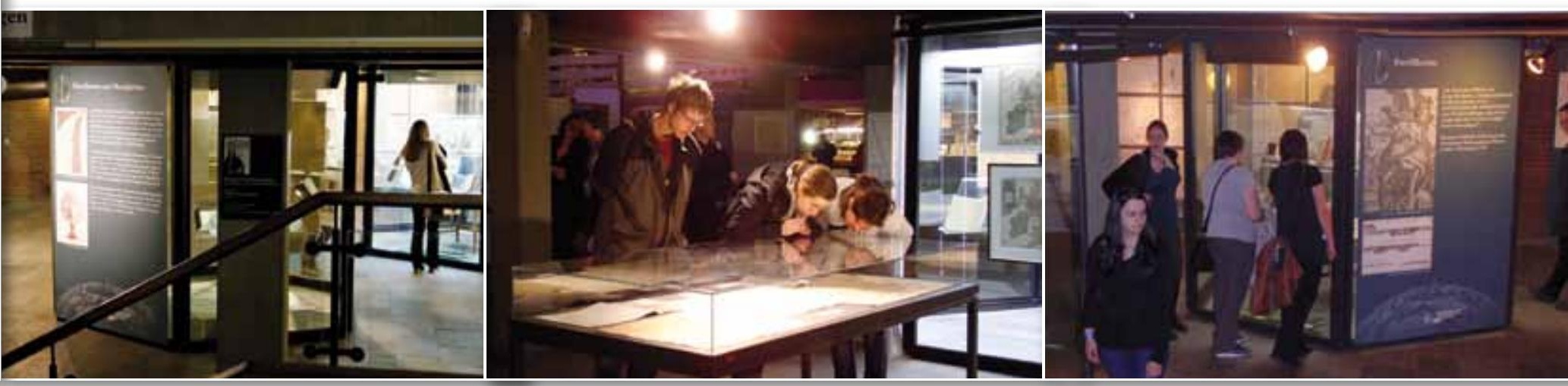



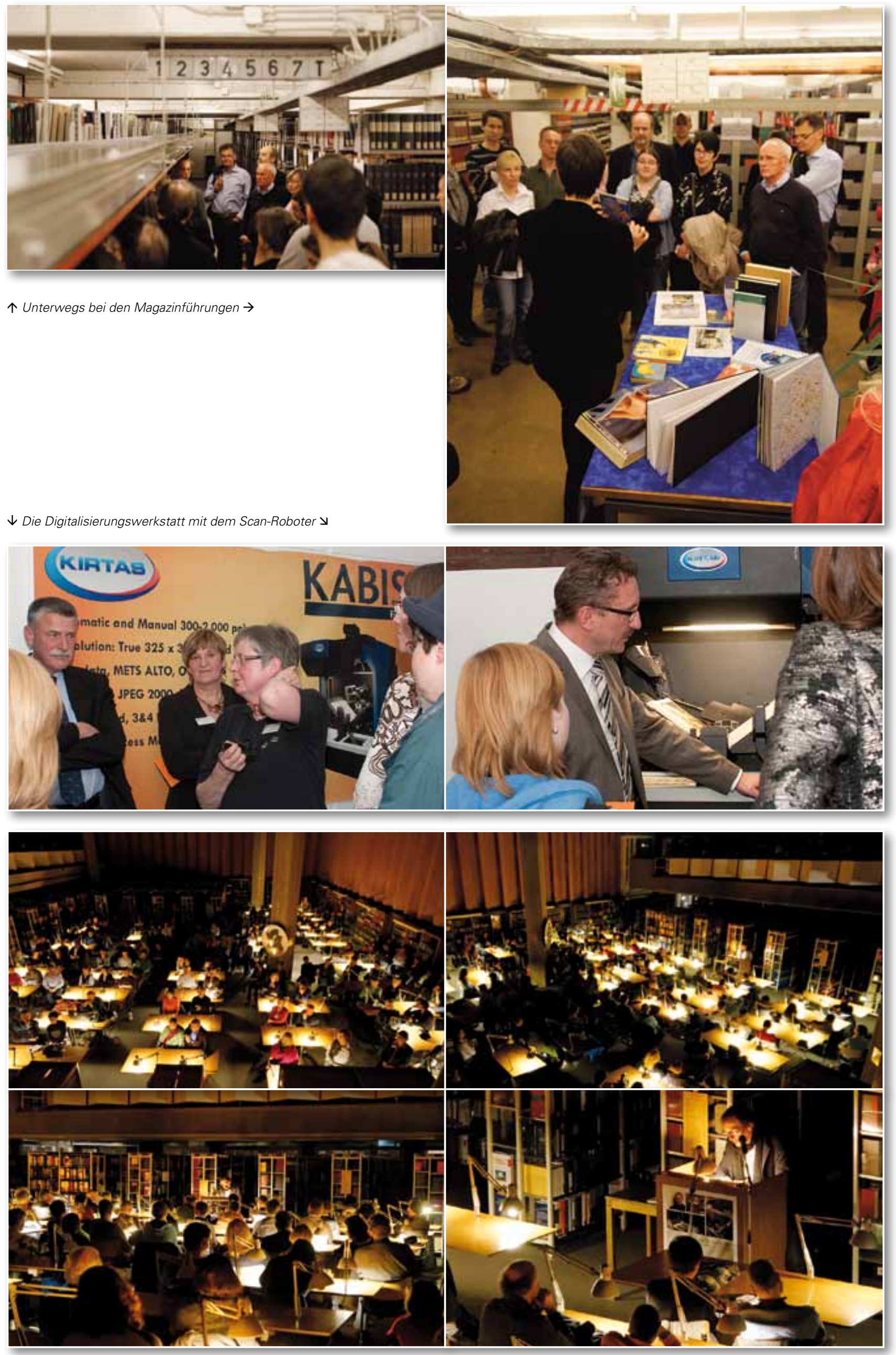

Der Lesesaal mal anders: Gut 130 Besucher lauschten gespannt der Lesung Wolfgang Schorlaus. 